\title{
Decreased Risk of Acute Graft-versus-Host Disease Using Reduced Intensity Conditioning Compared to Myeloablative Conditioning is Independent of Donor-Recipient T-cell Chimerism
}

\section{Olle Ringdén ${ }^{* 1,2}$, Mehmet Uzunel ${ }^{1}$, Behnam Sadeghi' ${ }^{1}$, Martin Solders ${ }^{1,2}$, Michael Uhlin ${ }^{1,2}$, Jonas Mattsson ${ }^{1,2}$ and Mats Remberger ${ }^{1,2}$}

${ }^{1}$ Department of Laboratory Medicine, Division of Therapeutic Immunology, Sweden

${ }^{2}$ Center for Allogeneic Stem Cell Transplantation, Karolinska University Hospital Huddinge, Sweden

\begin{abstract}
Background: It is not known if the reduced risk of graft-versus-host disease (GVHD) among patients receiving reduced intensity conditioning (RIC) as opposed to myeloablative conditioning (MAC) is due to differences in mixed donor-recipients chimerism, or to the intensity of the regimen.

Methods: We compared patients with acute myeloid leukemia (AML) selected for RIC $(n=47)$ to 46 patients selected for MAC before allogeneic hematopoietic stem cell transplantation (HSCT).

Results: Time to neutrophils $>0.5 \times 109 / \mathrm{L}$ was median 15 days in the MAC group, which was faster than 17 days in the RIC group $(p=0.001)$. MAC patients required more erythrocytes $(p=0.001)$ and platelet transfusions $(p=0.003)$. At four weeks, mixed donor-recipient T-cell chimerism was seen in $29 \%$ of the MAC patients and $46 \%$ of the RIC patients. Acute GVHD grades II-IV was $55 \%$ and $17 \%$ in the two groups, respectively $(p<0.001)$. In multivariate analysis, acute GVHD was reduced using RIC (hazards ratio (HR) 0.23, $p<0.001$ ), for year of HSCT (HR 1.27, $p=0.01$ ), but not for mixed donor-recipient T-cell chimerism (HR 1.11, $p=0.80$ ). Transplant-related mortality (TRM) at three years was $15 \%$ versus $13 \%$. Chronic GVHD and relapse were similar. Overall mortality was not affected by conditioning (HR 1.39, $\mathrm{p}=0.36)$.
\end{abstract}

Discussion: To conclude, patients treated with RIC had an increased risk of acute GVHD as opposed to recipients of MAC, which was due to less intense conditioning and not due to mixed donor T-cell chimerism.

Keywords: Acute myeloid leukemia; Reduced intensity conditioning; Myeloablative conditioning; Graft-versus-host disease; Donorrecipient chimerism

\section{Introduction}

Reduced intensity conditioning (RIC) has been used for one and a half decades to enable allogeneic hematopoietic stem cell transplantation (HSCT) in patients who are not fit for standard myeloablative conditioning (MAC) [1,2]. RIC takes advantage of the graft-versusleukemia (GVL) effect induced by immunocompetent cells in the graft rather than the antitumor effect of high-dose chemoradiotherapy. The GVL effect may be potentiated by donor lymphocyte infusions (DLIs) [3]. Most patients with leukemia, for example acute myeloid leukemia (AML), are selected for either RIC or MAC depending on risk factors for toxicity or relapse. Retrospective registry analyses suggest that there is more toxicity and transplant-related mortality (TRM) using MAC, but more relapse using RIC, and that the two methods have similar overall survival and leukemia-free survival (LFS) [4-6]. To our knowledge, there have only been two randomized studies comparing RIC and MAC, one German multicenter study and one toxicity study from our unit $[7,8]$. The multicenter study involved 195 patients and found no difference in TRM, relapse, disease-free survival, or overall survival between patients randomized to RIC or MAC. The randomized toxicity study showed that the RIC patients had significantly less toxicity such as mucositis, less cytomegalovirus (CMV) reactivation, and less hemorrhagic cystitis than the MAC patients [8].

Patients receiving RIC have been reported to have less acute GVHD than patients treated with MAC [4,9-11]. T-cell mixed donor-recipient chimerism have been reported to be associated with a decreased risk of acute GVHD [12-14]. RIC patients more often are mixed donor T-cell chimeras than those receiving MAC $[8,15]$. We wanted to analyze if mixed donor T-cell chimerism in RIC patients was a reason for the reduced risk of acute GVHD. We also wanted to compare other outcome parameters in patients selected for RIC or MAC based on age and comorbidity.

\section{Patients and Methods}

\section{Patient characteristics}

Adult patients with AML in first or second complete remission (CR) were selected for RIC $(n=47)$ if they were above 60 years of age or had comorbidity, such as organ impairment or infections, making them unsuitable for MAC. Patients $\leq 61$ years of age with possible high risk of relapse as judged by the referring physician were selected for MAC $(n=46)$. Patients $\leq 61$ years of age with no comorbidity and judged not to have an excessive risk of relapse were included in a prospective randomized toxicity study comparing RIC with MAC $(n=29)$ [8]. The randomized patients were excluded from the present study. All other AML patients submitted were included in this study. The characteristics regarding age, disease stage, type of donor, stem cell source, and cell dose in patients selected for MAC or RIC are given in (Table 1).

*Corresponding author: Olle Ringdén, Karolinska Institute, Division of Therapeutic Immunology, Karolinska University Hospital Huddinge, F79, SE-141 86 Stockholm Sweden, Tel: +46 8585 82672; Fax: +46 8746 6699; E-mail: Olle.Ringden@ki.se

Received July 15, 2014; Accepted October 27, 2014; Published October 29 2014

Citation: Ringdén O, Uzunel M, Sadeghi B, Solders M, Uhlin M, et al. (2014) Decreased Risk of Acute Graft-versus-Host Disease Using Reduced Intensity Conditioning Compared to Myeloablative Conditioning is Independent of DonorRecipient T-cell Chimerism. J Transplant Technol Res 4: 142. doi:10.4172/21610991.1000142

Copyright: ( 2014 Ringdén O, et al. This is an open-access article distributed under the terms of the Creative Commons Attribution License, which permits unrestricted use, distribution, and reproduction in any medium, provided the original author and source are credited. 
Citation: Ringdén O, Uzunel M, Sadeghi B, Solders M, Uhlin M, et al. (2014) Decreased Risk of Acute Graft-versus-Host Disease Using Reduced Intensity Conditioning Compared to Myeloablative Conditioning is Independent of Donor-Recipient T-cell Chimerism. J Transplant Technol Res 4: 142. doi:10.4172/2161-0991.1000142

\begin{tabular}{|c|c|c|c|}
\hline Characteristics & $\operatorname{MAC}(n=46)$ & $\operatorname{RIC}(n=47)$ & p-value \\
\hline \multicolumn{4}{|l|}{ Diagnosis: } \\
\hline AML & 46 & 47 & \\
\hline $\begin{array}{l}\text { Favorable cytogenetics/intermed/ } \\
\text { adverse }\end{array}$ & $5 / 28 / 2009$ & 2/33/11 & ns \\
\hline Disease stage (CR1/ > CR2) & $28 / 18$ & $22 / 25$ & ns \\
\hline $\operatorname{Sex}(M / F)$ & $28 / 18$ & $23 / 24$ & ns \\
\hline Age & $39(21-59)$ & $59(31-69)$ & $<0.001$ \\
\hline Donor: & & & 0.06 \\
\hline Sibling & 22 & 13 & \\
\hline MUD & 21 & 30 & \\
\hline Allele MM MUD & 3 & 4 & \\
\hline Donor sex (M/F) & $26 / 19$ & $29 / 18$ & ns \\
\hline Donor age & $37(18-66)$ & $34(20-71)$ & ns \\
\hline Female to male & 9 & 3 & 0.07 \\
\hline Stem cell source (BM/PBSCs) & Apr-42 & May-42 & ns \\
\hline NC dose $\left(\times 10^{6} / \mathrm{kg}\right)$ & $11.1(1.5-28.8)$ & $11.3(2.3-32.7)$ & ns \\
\hline CD34 dose $\left(\times 10^{6} / \mathrm{kg}\right)$ & $7.7(0.2-25.5)$ & $6.9(0.6-18.1)$ & ns \\
\hline \multicolumn{4}{|l|}{ GVHD prophylaxis: } \\
\hline CsA + MTX & 42 & 42 & \\
\hline $\mathrm{CsA}+\mathrm{MMF}$ & 0 & 1 & \\
\hline Tacrolimus + Sirolimus & 4 & 4 & \\
\hline \multicolumn{4}{|l|}{ Conditioning: } \\
\hline Busulfan-based & 40 & 41 & \\
\hline TBI-based & 4 & 0 & \\
\hline Chemo-based & 0 & $6^{*}$ & \\
\hline +ATG & $24(52 \%)$ & $41(87 \%)$ & $<0.001$ \\
\hline
\end{tabular}

Abbreviations: $\mathrm{AML}=$ Acute Myeloid Leukemia; $\mathrm{CR} 1=$ Complete Remission; $\mathrm{M}$ = Male; $\mathrm{F}=$ Female; $\mathrm{MUD}=$ Matched Unrelated Donor; $\mathrm{MM}=$ Mismatch; $\mathrm{BM}=$ Bone Marrow; PBSCs = Peripheral Blood Stem Cells; NC dose = Nucleated Cell dose; $\mathrm{CsA}=$ Cyclosporine; $\mathrm{MTX}=$ Methotrexate; $\mathrm{MMF}=$ Mycophenolate mofetil; $\mathrm{TBI}=$ Total Body Irradiation; ATG = Antithymocyte Globulin

Table 1: Characteristics of patients selected for myeloablative conditioning (MAC) or reduced intensity conditioning (RIC).

\section{Donors}

Grafts from HLA-identical sibling donors were given to 35 patients. An HLA-A, HLA-B, and DRB1-identical matched unrelated donor (MUD) typed with high-resolution typing was found for each of 51 patients [16]. Seven patients got grafts from allele-mismatched MUDs. Peripheral blood stem cells from a related or an unrelated donor were favored and were given to 84 patients $[17,18]$. Bone marrow grafts were given to nine patients (Table 1).

\section{Conditioning}

MAC consisted of busulfan $(4 \mathrm{mg} / \mathrm{kg} /$ day) divided into four doses and given for four days, combined with cyclophosphamide (Cy, 120mg/kg) [19]. Busulfan doses were monitored depending on pharmacokinetics [20]. RIC included $30 \mathrm{mg} / \mathrm{m}^{2} /$ day fludarabine for six days combined with $4 \mathrm{mg} / \mathrm{kg} /$ day busulfan for two days.

\section{Prophylaxis and Treatment of Graft-Versus-Host Disease}

Cyclosporine (CsA) combined with four doses of methotrexate (MTX) was given to 84 patients [21]. CsA was given i.v. on day -1 and day 0 , and thereafter orally with a dose ranging from 3 to $12 \mathrm{mg} / \mathrm{kg}$ to achieve a trough level of $100 \mathrm{ng} / \mathrm{ml}$ in recipients of grafts from HLAidentical siblings, and between 150 and $300 \mathrm{ng} / \mathrm{ml}$ in patients with MUDs [22]. One patient received CsA combined with mycophenolate mofetil and eight patients participated in a randomized study and were treated with tacrolimus $(0.1 \mathrm{mg} / \mathrm{kg} /$ day $)$ orally, aiming at trough levels between
5 and $15 \mathrm{ng} / \mathrm{ml}$ in combination with sirolimus to achieve trough levels of 5-10ng/ml [23]. Antithymocyte globulin (Thymoglobulin, Genzyme, Cambridge, MA) was given at a dose of $6-8 \mathrm{mg} / \mathrm{kg}$ to all recipients of grafts from MUDs and to seven patients with HLA-identical sibling grafts who were treated with RIC (Table 1) [24,25].

\section{Supportive Care}

Allopurinol was given to all patients during conditioning. To prevent hemorrhagic cystitis, forced diuresis, urinary alkalinization, and uromitexan $12 \mathrm{mg} / \mathrm{kg} /$ dose for six doses were given after each dose of cyclophosphamide. Patients were treated in hospital in reversed isolation or at home during the pancytopenic phase after conditioning [26]. When the number of copies of cytomegalovirus (CMV) DNA in blood was 1,000-2,000 using PCR, pre-emptive therapy with ganciclovir $(5 \mathrm{mg} / \mathrm{kg}$ i.v. twice daily), foscarnet $(90 \mathrm{mg} / \mathrm{kg}$ i.v. twice daily) or oral valganciclovir $(150 \mathrm{mg} / \mathrm{kg} /$ day twice a day) was given for two weeks or longer if PCR results remained positive. Details of the supportive care have already been published [22,26].

\section{Definitions}

The cytogenetic abnormalities in AML were classified as good: included $\mathrm{t}(18 ; 21), \mathrm{t}(15 ; 17)$, inv or del $(16 ;)$, poor included: $11 \mathrm{q} 23$ abnormalities, complex caryotype $\geq 3$ and abnormalities of chromosomes 5 and 7 [27]. All other abnormalities including trisomies were regarded as intermediate-risk cytogenetic abnormalities. Bacterial septicemia was defined as a positive blood culture during a febrile episode with $\geq 38.5^{\circ} \mathrm{C}$. Acute GVHD was graded according to the Seattle criteria [28]. Chronic graft-versus-host disease was defined as limited or extensive, or as mild, moderate or severe, based on the judgment of the treating physician [29,30]. CMV infection was defined as CMV DNA positivity by PCR and CMV disease was defined as symptomatic organ involvement. Hemorrhagic cystitis was defined as painful hematuria with a negative urine culture without any other explanation. It was graded from 1 to 5 according to NCI criteria [31]. AML relapse was defined as $>20 \%$ blasts in the bone marrow, or leukemia in extra medullary organs.

\section{Chimerism}

Chimerism was analyzed $1,3,6$, 9, and 12 months after HSCT. PCR amplification of variable numbers of tandem repeats was used to evaluate the degree of donor and recipient chimerism in CD19+, $\mathrm{CD} 3+, \mathrm{CD} 33+$ cells enriched using magnetic beads (Dynal, Oslo, Norway) as previously described in detail [32]. Donor chimerism (DC) was defined as $<5 \%$ recipient cells. Until April 2005, chimerism analysis was based on mini-satellites. After that date, a real-time PCR method based on single nucleotide polymorphism (SNP) was used, which has also been described previously [33]. In this study, we used $\mathrm{CD} 3+$ chimerism at one month for evaluation, because this was the average date of appearance of GVHD.

\section{Statistics}

Comparisons between groups were performed using Fisher's exact test, the chi-square test, or the Mann-Whitney U-test. The probabilities of survival and LFS were estimated using the Kaplan-Meier method and compared with a log-rank test (Mantel-Haenszel) [34]. TRM, GVHD, and relapse were estimated using cumulative incidence curves, taking competing events into consideration [35]. Factors with a p-value of $\mathrm{p}<0.1$ or known risk-factors were included in the multivariate analysis. Analysis was performed using the CMPRSK package (developed by 
Citation: Ringdén O, Uzunel M, Sadeghi B, Solders M, Uhlin M, et al. (2014) Decreased Risk of Acute Graft-versus-Host Disease Using Reduced Intensity Conditioning Compared to Myeloablative Conditioning is Independent of Donor-Recipient T-cell Chimerism. J Transplant Technol Res 4: 142. doi:10.4172/2161-0991.1000142

Page 3 of 8

Gray, June 2001), Splus 6.2 software (Insightful, Seattle, WA) and Statistica software (StatSoft, Tulsa, OK).

\section{Results}

\section{Engraftment, transfusions, and discharge}

All patients but one in each group had engraftment. Median time to neutrophil counts $>0.5 \times 109 / \mathrm{L}$ was 15 (range 11-35) in the MAC group and $17(0-34)$ in the RIC group (Figure 1, $\mathrm{p}=0.001$ ). Time to reach platelet counts $>30 \times 109 / \mathrm{L}$ was the same in both groups: 13 (9$31)$ and $13(0-40)$, respectively. RIC patients received fewer erythrocyte transfusions, median $2(0-12)$, than MAC patients $(2(0-14), \mathrm{p}=$ 0.003). RIC patients also required fewer platelet transfusions: $1(0-6)$ as opposed to $2(0-18)$ in the MAC group ( $p=0.001)$. Granulocyte transfusions due to infection and/or severe mucositis were given to seven MAC patients and two RIC patients $(\mathrm{p}=0.36)$. Median time to discharge from the hospital was 20 (12-69) in the MAC patients and 20 (15-42) in the RIC patients (ns).

\section{Infections}

Herpes simplex virus infection was seen in 8 of the MAC patients $(17 \%)$ and 3 of the RIC patients $(6 \%)(p=0.12)$. Bacteremia was diagnosed in 15 patients in the MAC group (33\%) and in 8 patients in the RIC group $(17 \%)(\mathrm{p}=0.1)$. CMV reactivation was diagnosed by PCR in 26 patients in the MAC group (56\%) and in 27 patients in the RIC group (57\%). The corresponding Figure s for CMV disease in the two groups were $4(9 \%)$ and $3(6 \%)$.

\section{Graft-versus-host disease and chimerism}

Of the MAC patients, 14 did not experience GVHD, as opposed to 29 in the RIC group. The incidence of acute GVHD of grade I, grade II, and grades III-IV was 7, 20, and 5 in the MAC group and 9, 8, and 1 in the RIC group $(\mathrm{p}<0.001)$. The cumulative incidence of grade II-
IV acute GVHD was 55\% in the MAC patients and $17 \%$ in the RIC patients $(\mathrm{p}<0.001)$ (Figure $2 \mathrm{a})$. At one month, 46\% (13/28) of the RIC patients were mixed T-cell chimeras as compared to $29 \%(10 / 35)$ among the MAC patients. T-cell chimerism did not differ between the RIC patients and the MAC patients (Figure 3a). Among these patients, there was no correlation between donor T-cell chimerism and acute GVHD grades 0 -I versus II-IV (Figure $3 \mathrm{~b}$ ). In multivariate analysis for factors associated with acute GVHD, RIC $(p<0.001)$ and year of transplantation $(\mathrm{p}=0.01)$ were associated with reduced risk of acute GVHD, but chimerism was not $(\mathrm{p}=0.80)$ (Table 2). Chronic GVHD was diagnosed in 13 of the MAC patients, 5 with limited disease and 8 with extensive disease. In the RIC patients, 10 had chronic GVHD; of these, 6 had limited disease and 4 had extensive disease. Mild, moderate, and severe chronic GVHD was seen in 9, 2, and 2 of the MAC patients and in 9, 1, and none of the RIC patients, respectively. The cumulative incidence of chronic GVHD at four years was $32 \%$ in the MAC group, as compared to $22 \%$ in the RIC group $(\mathrm{p}=0.45)$ (Figure $2 \mathrm{~b}$ ).

Transplant-related mortality, relapse, overall survival, and leukemia-free survival

TRM at three years was $15 \%$ in the MAC group and $13 \%$ in the RIC group (Figure 2c). The cumulative probability of relapse was significantly higher in the RIC group in univariate analysis, being $44 \%$ at five years, as opposed to $24 \%$ in the MAC patients $(\mathrm{p}=0.01)$ (Figure $2 \mathrm{~d}$ ). In multivariate analysis of factors associated with relapse, RIC was not associated with an increased risk of relapse compared to MAC (hazards ratio (HR) 1.62, $\mathrm{p}=0.34$ ) (Table 2). Patients treated with CsA and MTX had a reduced risk of relapse $(\mathrm{p}<0.01)$ and those treated with ATG had an increased risk of relapse $(\mathrm{p}=0.01)$ (Table 2).

Survival at five years was $67 \%$ in the MAC group and $48 \%$ in the RIC group ( $p=0.08$ ) (Figure 4a). In multivariate analysis, there was no difference in survival between the RIC patients and the MAC patients. Factors associated with reduced survival were adverse cytogenetics ( $p$

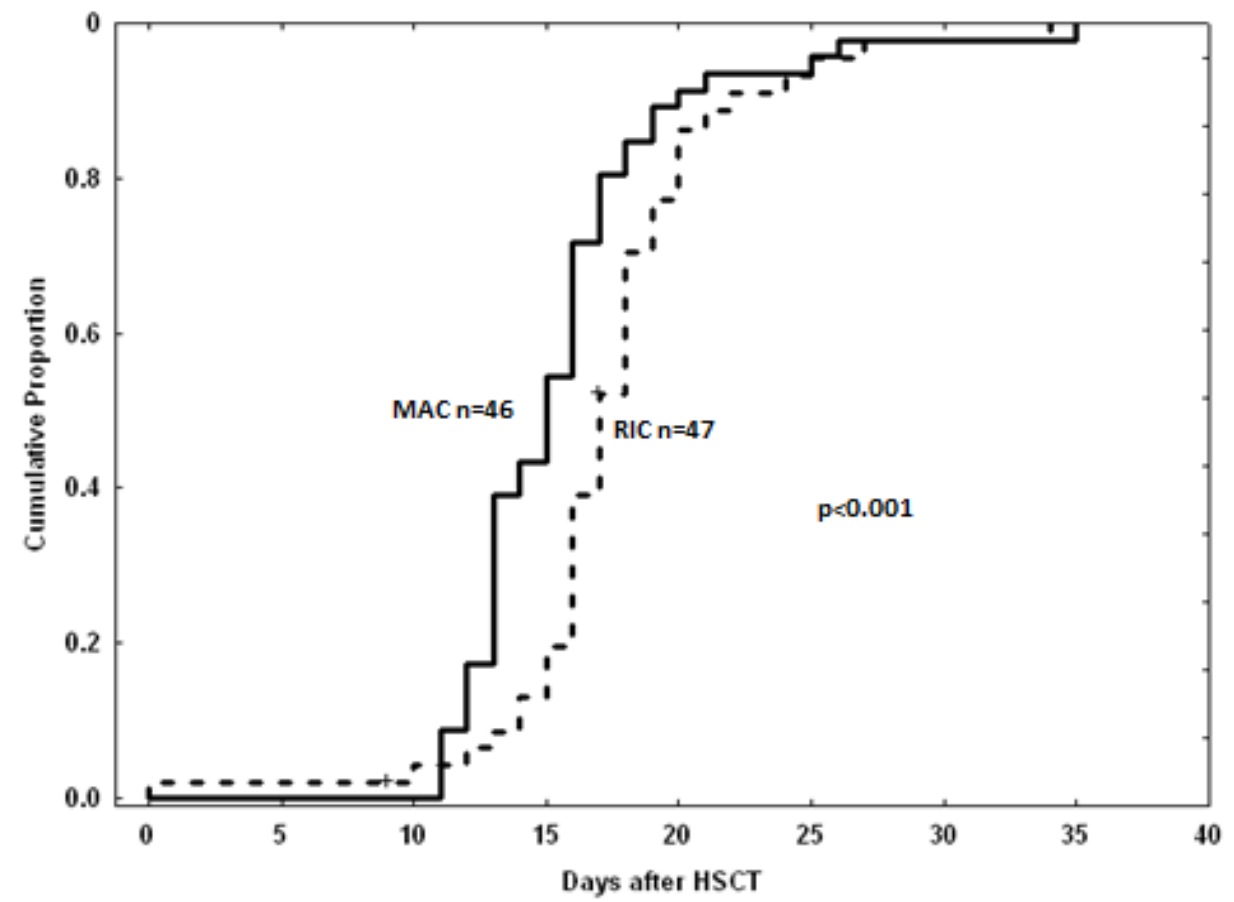

Figure 1: Time to and cumulative incidence of absolute neutrophil count $>0.5 \times 10^{9}$ in patients selected for myeloablative conditioning (MAC) or reduced intensity conditioning (RIC). 
Citation: Ringdén O, Uzunel M, Sadeghi B, Solders M, Uhlin M, et al. (2014) Decreased Risk of Acute Graft-versus-Host Disease Using Reduced Intensity Conditioning Compared to Myeloablative Conditioning is Independent of Donor-Recipient T-cell Chimerism. J Transplant Technol Res 4: 142. doi:10.4172/2161-0991.1000142

a.

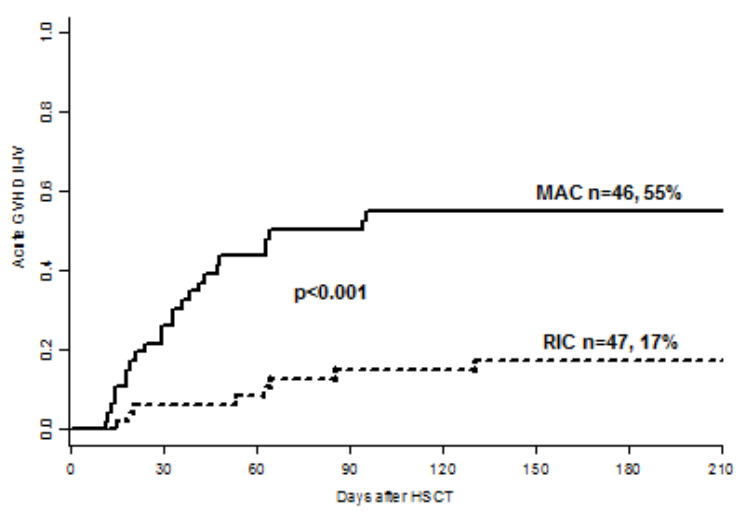

c.

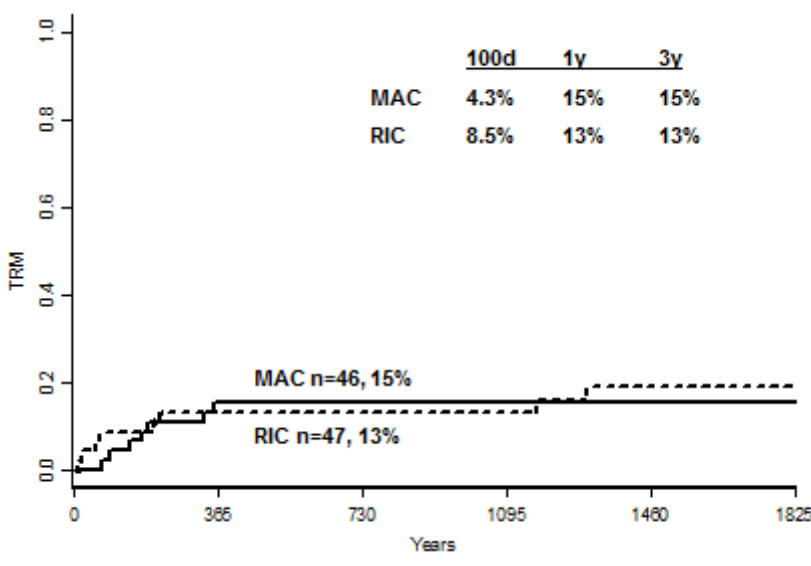

b.

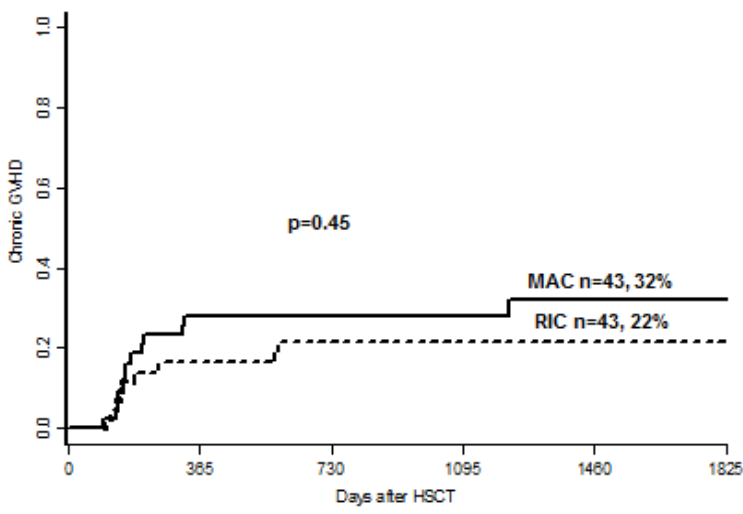

d.

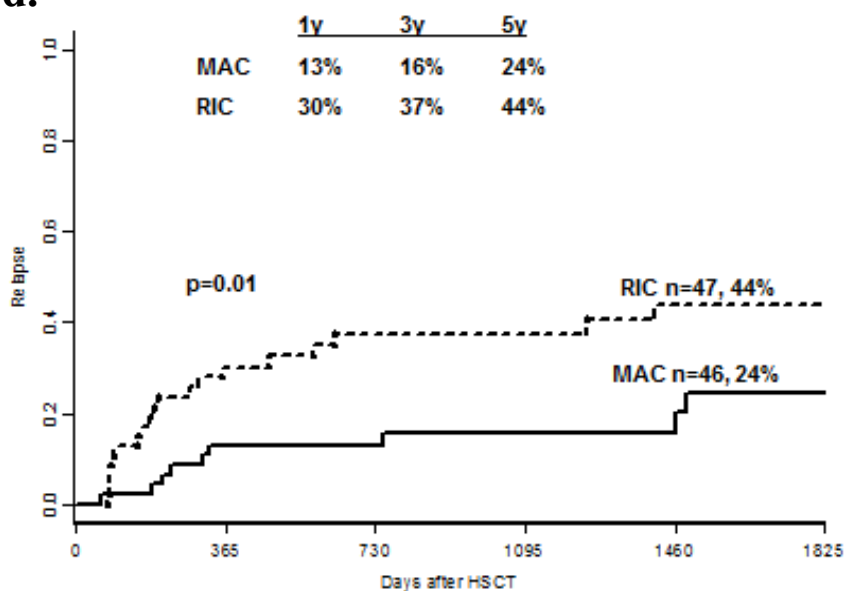

Figure 2: a. Time to and cumulative incidence of acute GVHD, grades II-IV, in patients selected for myeloablative conditioning (MAC) or reduced intensity conditioning (RIC) ( $\mathrm{p}<0.001$ ). Multivariate analysis (HR 0.27, $\mathrm{p}<0.01$ ). b. Time to and cumulative incidence of chronic GVHD in patients selected for myeloablative conditioning (MAC) or reduced intensity conditioning (RIC) $(p=0.45)$. c. Time to and cumulative incidence of transplant-related mortality (TRM) in patients selected for myeloablative conditioning (MAC) or reduced intensity conditioning (RIC). d. Time to and cumulative incidence of leukemic relapse in patients selected for myeloablative conditioning (MAC) or reduced intensity conditioning $(\mathrm{RIC})(\mathrm{p}=0.01)$. Multivariate analysis (HR 1.62, $p=0.34)$.

a.

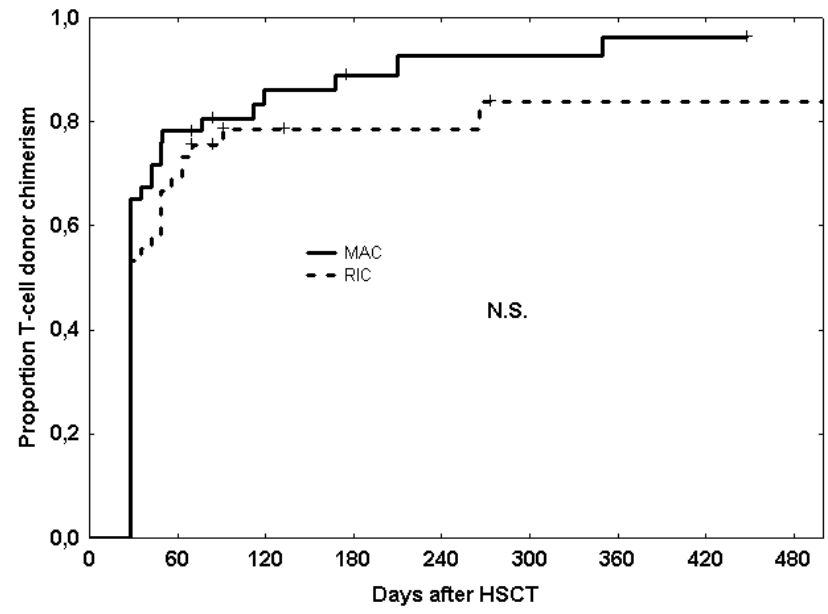

b.

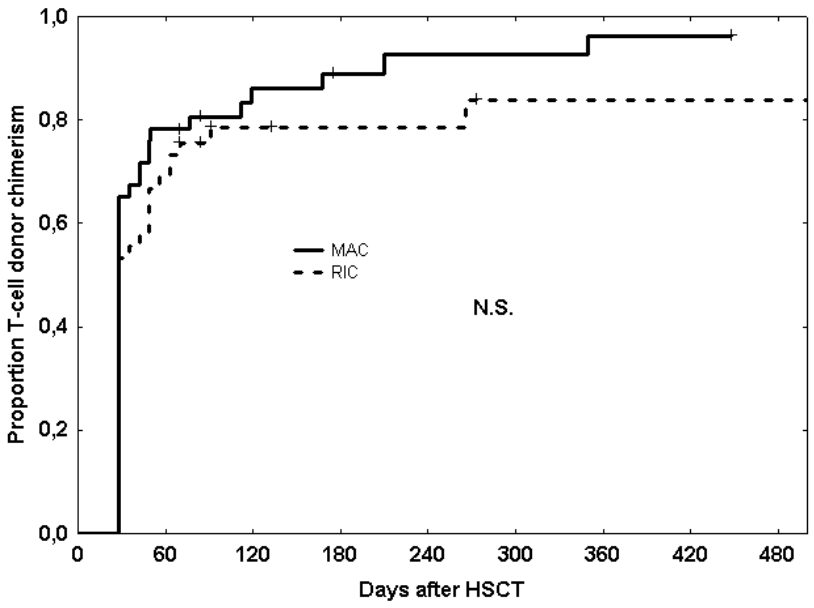

Figure 3: a. Time to and cumulative incidence of T-cell donor chimerism in patients treated with reduced intensity conditioning (RIC) or myeloablative conditioning (MAC). b. Time to and cumulative incidence of T-cell chimerism in patients who developed grades 0-I acute GVHD and those who developed grades II-IV acute GVHD. 
Citation: Ringdén O, Uzunel M, Sadeghi B, Solders M, Uhlin M, et al. (2014) Decreased Risk of Acute Graft-versus-Host Disease Using Reduced Intensity Conditioning Compared to Myeloablative Conditioning is Independent of Donor-Recipient T-cell Chimerism. J Transplant Technol Res 4: 142. doi:10.4172/2161-0991.1000142

Page 5 of 8

\begin{tabular}{|c|c|c|c|}
\hline Factor & Relative hazards & $95 \%$ confidence interval & p-value \\
\hline \multicolumn{4}{|l|}{ Acute GVHD II-IV } \\
\hline RIC vs. MAC & 0.23 & $0.10-0.51$ & $<0.00$ \\
\hline Year of HSCT & 1.27 & $1.07-1.52$ & 0.01 \\
\hline Mixed chimerism & 0.9 & $0.40-2.00$ & 0.8 \\
\hline \multicolumn{4}{|l|}{ Relapse } \\
\hline RIC vs. MAC & 1.62 & $0.61-4.31$ & 0.34 \\
\hline $\mathrm{CsA}+\mathrm{MTX}$ & 0.35 & $0.15-0.81$ & 0.014 \\
\hline ATG & 4.48 & $1.36-14.8$ & 0.014 \\
\hline Acute GVHD I-IV & 0.45 & $0.21-0.99$ & $<0.05$ \\
\hline \multicolumn{4}{|l|}{ Mortality } \\
\hline RIC vs. MAC & 1.39 & $0.69-2.81$ & 0.36 \\
\hline Adverse cytogenetics & 2.31 & $1.14-4.68$ & 0.02 \\
\hline ATG & 2.64 & $1.00-7.06$ & 0.05 \\
\hline Bone marrow & 2.33 & $1.04-2.39$ & 0.04 \\
\hline \multicolumn{4}{|c|}{ Transplant failure (opposite of leukemia-free survival) } \\
\hline RIC vs. MAC & 1.61 & $0.85-3.06$ & 0.14 \\
\hline ATG & 3.95 & $1.51-10.3$ & 0.005 \\
\hline Adverse cytogenetics & 2.13 & $1.10-4.12$ & 0.025 \\
\hline
\end{tabular}

Abbreviations: RIC = Reduced Intensity Conditioning; MAC = Myeloablative Conditioning; $\mathrm{ATG}=$ Antithymocyte Globulin; $\mathrm{CsA}=$ Cyclosporine; $\mathrm{MTX}=$ Methotrexate; GVHD = Graft-Versus-Host Disease.

Table 2: Multivariate analysis for acute GVHD of grades II-IV, relapse, mortality, and transplant failure (leukemia-free survival).

a.

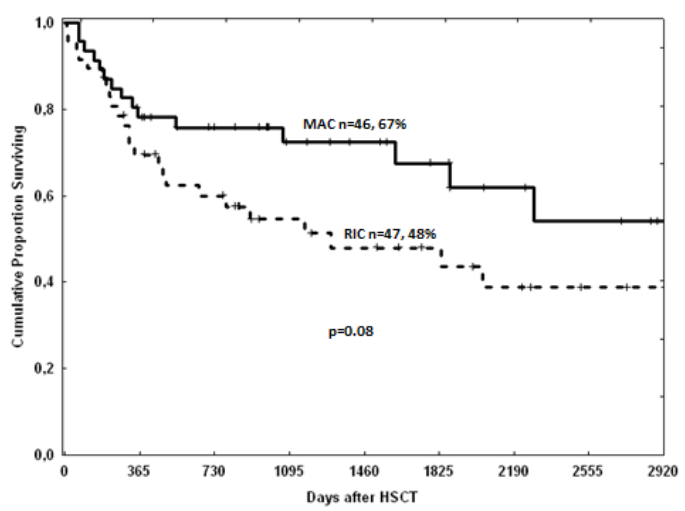

$=0.02)$, treatment with ATG $(\mathrm{p}=0.05)$, and bone marrow graft rather than PBSCs $(\mathrm{p}=0.04)($ Table 2$)$.

LFS at five years was $60 \%$ in the MAC patients, as opposed to $37 \%$ in the RIC patients $(\mathrm{p}=0.017)$ (Figure $4 \mathrm{~b})$. LSF for patients with intermediate-risk cytogenetics was $61 \%$ and $44 \%$ in the two groups, respectively $(\mathrm{p}=0.07)$ (Figure $4 \mathrm{c})$. For patients with adverse-risk cytogenetics, three-year survival was $44 \%$ in the MAC patients and $45 \%$ in the RIC patients. In multivariate analysis, there was no difference in LFS between patients receiving MAC or RIC (Table 2). Factors associated with reduced LFS were adverse cytogenetics and ATG.

Causes of death for the MAC and RIC patients were: GVHD (4 and 1 , respectively), relapse (5 and 14), infection (5 and 6), and others (1 and 3$)$.

\section{Discussion}

Like most studies published so far that have compared MAC and RIC in AML patients undergoing HSCT, this study included patients who were selected, because the patients were thought to benefit from one conditioning rather than the other. This selection introduces an obvious bias, with younger and fitter patients selected for MAC. This may be the reason that the MAC group had faster engraftment of neutrophils. This contrasts with a previous retrospective analysis in AML patients receiving grafts from unrelated donors, where the RIC patients

b.

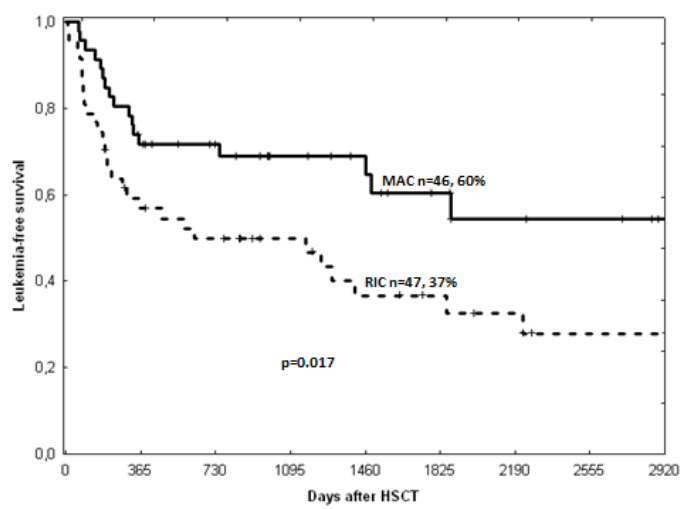

c.

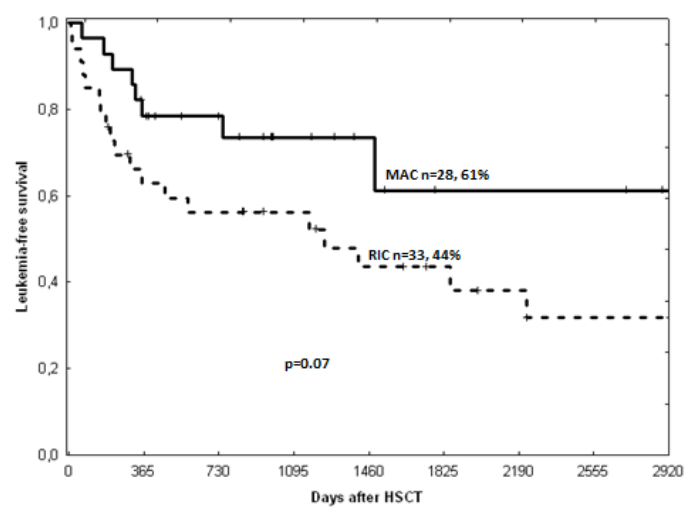

Figure 4: a. Probability of survival in patients selected for treatment with myeloablative conditioning (MAC) or reduced intensity conditioning (RIC) $(p=0.08)$. Fiveyear survival was $67 \%$ in the MAC group and $48 \%$ in the RIC group. Multivariate analysis (RH 1.39, $p=0.36)$. b. Probability of leukemia-free survival (LFS) in patients with acute myeloid leukemia (AML) selected for myeloablative conditioning (MAC) or reduced intensity conditioning (RIC) $(p=0.017)$. Six-year LFS was 60\% in the MAC group and $37 \%$ in the RIC group. Multivariate analysis (RH 1.61, $p=0.14$ ). c. Probability of leukemia-free survival in patients with acute myeloid leukemia (AML) selected for myeloablative conditioning (MAC) or reduced intensity conditioning (RIC) with intermediate-risk cytogenetics ( $p=0.07)$. Five-year survival was $61 \%$ in the MAC group and $44 \%$ in the RIC group. 
Citation: Ringdén O, Uzunel M, Sadeghi B, Solders M, Uhlin M, et al. (2014) Decreased Risk of Acute Graft-versus-Host Disease Using Reduced Intensity Conditioning Compared to Myeloablative Conditioning is Independent of Donor-Recipient T-cell Chimerism. J Transplant Technol Res 4: 142. doi:10.4172/2161-0991.1000142

Page 6 of 8

had faster neutrophil engraftment [6]. Despite the faster neutrophil engraftment in the MAC group, time to discharge was the same in the two study groups (20 days). The reason that the MAC patients were not discharged earlier despite faster neutrophil engraftment is probably due to the more toxic regimen giving rise to more mucositis, as was found in the two randomized studies $[7,8]$. Because of this, the MAC patients needed more total parenteral nutrition and it took some days before oral intake was sufficient for discharge [8]. More transfusions of erythrocytes and platelets were needed in the MAC patients, which is in keeping with the results of the randomized toxicity study.

In the present study, where less fit patients were selected for RIC, the incidence of CMV reactivation was the same as in the MAC group. This has also been seen in another study comparing HSCT patients selected for RIC or MAC [36]. It contrasts with the results of the randomized study with similar, fit patients where CMV infection was significantly less common in RIC patients than in MAC patients [8]. This finding highlights the fact that by selecting for MAC or RIC, these are different patient populations which of course influence outcome in various ways. With less fit patients in the RIC group, the risk of CMV infection is the same as with more fit patients treated with MAC.

Acute GVHD was more common in the MAC group than in the RIC group, both in univariate analysis and multivariate analysis, taking into consideration differences between the two groups such as differences in age, unrelated donor transplants, female donor to male recipient, and use of ATG (Table 2). RIC has previously been reported to be associated with less acute GVHD than MAC [4,9-11]. One reason for the increased risk of GVHD using MAC may be that tissue toxicity induced by chemoradiotherapy causes release of cytokines that are of importance for the development of GVHD $[37,38]$. Another reason for the reduced risk of acute GVHD using RIC rather than MAC may be that mixed donor T-cell chimerism is more common with RIC $[8,15]$ and that donor T-cell chimerism is more associated with acute GVHD than mixed chimerism [14]. Animal studies have also shown that mixed chimerism is associated with a reduced risk of GVHD [39,40]. In the present analysis, mixed recipient-donor chimerism had no effect on GVHD in uni- or multivariate analysis. This highlights the fact that RIC is associated with a reduced risk of acute GVHD despite the fact that RIC patients are older than the MAC patients and that acute GVHD is otherwise more severe in older patients. Thus, toxicity induced by conditioning was more important for the development of acute GVHD than achieving full donor T-cell chimerism.

The incidence of chronic GVHD was not significantly different in the RIC and MAC groups (Figure 3). This is in keeping with the results of most of the other studies [3-8,11,41]. However, a few studies have shown that RIC patients had less chronic GVHD than MAC patients $[4,9]$. There is a correlation between acute and chronic GVHD, which would speak in favor of a reduced risk of chronic GVHD in patients treated with RIC rather than MAC [42-44]. However, the incidence of chronic GVHD also increases with increasing age. Thus, it is probable that these two factors counterbalance each other-with no difference in incidence of chronic GVHD between patients treated with RIC and $\mathrm{MAC}$, as seen in this study.

TRM was similar in the two groups (Figure 2a). This study demonstrates that selection of RIC for patients with high age or comorbidity gives low TRM: $13 \%$ at three years, which was similar to that for MAC (Figure 2c). This is supported by the results of the two randomized studies $[7,8]$. However, one study in HLA-identical siblings found a lower probability of TRM in the RIC patients than in the MAC patients [6]. A study from the Center for International
Blood and Marrow Transplant Research (CIBMTR) found that there was no significant difference in TRM using MAC, RIC, or non-myeloablative conditioning [5]. A study from the European Group for Blood and Marrow Transplantation (EBMT) using unrelated donors found that in patients over 50 years of age, TRM was significantly higher in the MAC group than in the RIC group, whereas in patients less than 50 years of age there was no significant difference in TRM using RIC or MAC [6].

Relapse was significantly more common in the RIC group in univariate analysis, but not in multivariate analysis when adjusting for differences in patient characteristics between the groups. Several large retrospective studies have shown that relapse is probably higher with RIC than with MAC [4-6]. This might be expected, because with more chemoradiotherapy, leukemia cells are killed more efficiently, which is supported by prospective randomized studies [45]. However, a randomized study showed a similar incidence of relapse in patients who were randomized to RIC or MAC [7]. However, the low probability of relapse in the MAC group, $24 \%$ at five years, suggests that MAC may be selected in young patients with an expected high risk of relapse. There are data that show that the GVL effect may be more effective using RIC than using MAC [46]. A large study from the CIBMTR recently suggested that in patients with AML or myelodysplastic syndrome, the GVL effect using RIC results in improved survival and LFS, both short-term and long-term, compared to MAC. These data suggested that RIC should be selected more often as conditioning, even for goodrisk patients with AML and MDS. The randomized toxicity study also showed that RIC should be selected more often, because this results in significantly less toxicity and suffering than with MAC [8].

Overall survival and LFS were encouraging in the MAC patients. The LFS at six years was $60 \%$ (Figure $4 \mathrm{~b}$ ). The corresponding LFS in the RIC patients was only $37 \%$, but this was a selected group with co-morbidities and high age and it was therefore acceptable. ATG decreased survival, and especially LFS, due to an increased risk of relapse. Using unrelated donors, ATG is beneficial because it reduces acute GVHD and also TRM [47]. Especially when using RIC and HLAidentical sibling transplants, ATG should not be given and a higher PBSC cell dose should be aimed for to reduce the risk of graft failure and relapse, and perhaps improve LFS [25]. When using an unrelated donor, the ATG dose may be lower in RIC patients than in MAC patients to maintain a strong GVL effect.

This is a registry retrospective analysis and therefore, the data has to be interpreted with caution. Even if all known risk-factors were included in the multivariate analysis, there may be unknown factors of importance which were not included.

To conclude, when we selected AML patients of high age, and with comorbidity, for RIC, TRM was low and similar to that in more fit patients treated with MAC. One reason for this may be that the risk of acute GVHD was reduced with RIC. We also found that conditioning, i.e. RIC, was more important than mixed chimerism for reduction of acute GVHD. Although there was higher relapse with RIC in univariate analysis, there was no significant difference in the multivariate analysis. Survival and LFS with RIC, although inferior to that with MAC, was acceptable in this high-risk category. Thus, selection for RIC or MAC based on age and comorbidity appears valid according to the results of the present study.

\section{Acknowledgements}

We thank the staff at the Center for Allogeneic Stem Cell Transplantation and Hematology for competent and 
Citation: Ringdén O, Uzunel M, Sadeghi B, Solders M, Uhlin M, et al. (2014) Decreased Risk of Acute Graft-versus-Host Disease Using Reduced Intensity Conditioning Compared to Myeloablative Conditioning is Independent of Donor-Recipient T-cell Chimerism. J Transplant Technol Res 4: 142. doi:10.4172/2161-0991.1000142

compassionate care of the patients. We also thank Inger Holmström for expert typing of this manuscript. This study was supported by grants from the Swedish Cancer Society (CAN2011/419), the Swedish Research Council (K201164X-05971-31-6), the Children's Cancer Foundation (PROJ09/093), the Cancer Society in Stockholm (111293), and Karolinska Institutet.

The authors have no conflicts of interest to disclose.

\section{References}

1. Giralt S, Estey E, Albitar M, van Besien K, Rondón G, et al. (1997) Engraftment of allogeneic hematopoietic progenitor cells with purine analog-containing chemotherapy: harnessing graft-versus-leukemia without myeloablative therapy. Blood 89: 4531-4536.

2. Slavin S, Nagler A, Naparstek E, Kapelushnik Y, Aker M, et al. (1998) Nonmyeloablative stem cell transplantation and cell therapy as an alternative to conventional bone marrow transplantation with lethal cytoreduction for the treatment of malignant and nonmalignant hematologic diseases. Blood 91 : 756-763.

3. Kolb HJ, Mittermüller J, Clemm C, Holler E, Ledderose G, et al. (1990) Donor leukocyte transfusions for treatment of recurrent chronic myelogenous leukemia in marrow transplant patients. Blood 76: 2462-2465.

4. Aoudjhane M, Labopin M, Gorin NC, Shimoni A, Ruutu T, et al. (2005) Comparative outcome of reduced intensity and myeloablative conditioning regimen in HLA identical sibling allogeneic haematopoietic stem cell transplantation for patients older than 50 years of age with acute myeloblastic leukaemia: a retrospective survey from the Acute Leukemia Working Party (ALWP) of the European group for Blood and Marrow Transplantation (EBMT). Leukemia 19: 2304-2312.

5. Luger SM, Ringdén O, Zhang MJ, Pérez WS, Bishop MR, et al. (2012) Similar outcomes using myeloablative vs reduced-intensity allogeneic transplan preparative regimens for AML or MDS. Bone Marrow Transplant 47: 203-211.

6. Ringdén O, Labopin M, Ehninger G, Niederwieser D, Olsson R, et al. (2009) Reduced intensity conditioning compared with myeloablative conditioning using unrelated donor transplants in patients with acute myeloid leukemia. $J$ Clin Oncol 27: 4570-4577.

7. Bornhäuser M, Kienast J, Trenschel R, Burchert A, Hegenbart U, et al. (2012) Reduced-intensity conditioning versus standard conditioning before allogeneic haemopoietic cell transplantation in patients with acute myeloid leukaemia in first complete remission: a prospective, open-label randomised phase 3 trial. Lancet Oncol 13: 1035-1044.

8. Ringdén O, Erkers T, Aschan J, Garming-Legert K, Le Blanc K, et al. (2013) A prospective randomized toxicity study comparing reduced-intensity and myeloablative conditioning in patients with myeloid leukemia undergoing allogeneic hematopoietic stem cell transplantation. J Intern Med 274: 153-162.

9. Couriel DR, Saliba RM, Giralt S, Khouri I, Andersson B, et al. (2004) Acute and chronic graft-versus-host disease after ablative and nonmyeloablative conditioning for allogeneic hematopoietic transplantation. Biol Blood Marrow Transplant 10: 178-185.

10. Pérez-Simón JA, Díez-Campelo $M$, Martino $R$, Brunet $S$, Urbano $A$, et al. (2005) Influence of the intensity of the conditioning regimen on the characteristics of acute and chronic graft-versus-host disease after allogeneic transplantation. Br J Haematol 130: 394-403.

11. Sureda A, Robinson S, Canals C, Carella AM, Boogaerts MA, et al. (2008) Reduced-intensity conditioning compared with conventional allogeneic stem-cell transplantation in relapsed or refractory Hodgkin's lymphoma: an analysis from the Lymphoma Working Party of the European Group for Blood and Marrow Transplantation. J Clin Oncol 26: 455-462.

12. Frassoni F, Strada $P$, Sessarego M, Miceli S, Corvò R, et al. (1990) Mixed chimerism after allogeneic marrow transplantation for leukaemia: correlation with dose of total body irradiation and graft-versus-host disease. Bone Marrow Transplant 5: 235-240.

13. Huss R, Deeg HJ, Gooley T, Bryant E, Leisenring W, et al. (1996) Effect of mixed chimerism on graft-versus-host disease, disease recurrence and survival after HLA-identical marrow transplantation for aplastic anemia or chronic myelogenous leukemia. Bone Marrow Transplant 18: 767-776.

14. Mattsson J, Uzunel M, Remberger M, Ringdén O (2001) T cell mixed chimerism is significantly correlated to a decreased risk of acute graft-versushost disease after allogeneic stem cell transplantation. Transplantation 71 433-439.

15. Stikvoort A, Gertow J, Sundin M, Remberger M, Mattsson J, et al. (2013) Chimerism patterns of long-term stable mixed chimeras posthematopoietic stem cell transplantation in patients with nonmalignant diseases: follow-up of long-term stable mixed chimerism patients. Biol Blood Marrow Transplant 19: 838-844.

16. Schaffer M, Aldener-Cannavá A, Remberger M, Ringdén O, Olerup O (2003) Roles of HLA-B, HLA-C and HLA-DPA1 incompatibilities in the outcome of unrelated stem-cell transplantation. Tissue Antigens 62: 243-250.

17. Schmitz N, Bacigalupo A, Hasenclever D, Nagler A, Gluckman E, et al. (1998) Allogeneic bone marrow transplantation vs filgrastim-mobilised periphera blood progenitor cell transplantation in patients with early leukaemia: firs results of a randomised multicentre trial of the European Group for Blood and Marrow Transplantation. Bone Marrow Transplant 21: 995-1003.

18. Ringdén $O$, Remberger $M$, Runde $V$, Bornhäuser $M$, Blau IW, et al (1999) Peripheral blood stem cell transplantation from unrelated donors: comparison with marrow transplantation. Blood 94: 455-464.

19. Ringdén O, Ruutu T, Remberger M, Nikoskelainen J, Volin L, et al. (1994) A randomized trial comparing busulfan with total body irradiation as conditioning in allogeneic marrow transplant recipients with leukemia: a report from the Nordic Bone Marrow Transplantation Group. Blood 83: 2723-2730.

20. Hassan Z, Ljungman P, Ringdén O, Winiarski J, Nilsson C, et al. (2001) Pharmacokinetics of liposomal busulphan in man. Bone Marrow Transplant 27: 479-485.

21. Storb R, Deeg HJ, Pepe M, Appelbaum F, Anasetti C, et al. (1989) Methotrexate and cyclosporine versus cyclosporine alone for prophylaxis of graft-versus-host disease in patients given HLA-identical marrow grafts for leukemia: long-term follow-up of a controlled trial. Blood 73: 1729-1734.

22. Ringdén O, Remberger M, Persson U, Ljungman $P$, Aldener A, et al. (1995) Similar incidence of graft-versus-host disease using HLA-A, -B and -DR identical unrelated bone marrow donors as with HLA-identical siblings. Bone Marrow Transplant 15: 619-625.

23. Ringdén O, Remberger M, Dahllöf G, Garming-Legert K, Karlsson H, et al. (2011) Sirolimus and tacrolimus as immune prophylaxis compared to cyclosporine with or without methotrexate in patients undergoing allogeneic haematopoietic stem cell transplantation for non-malignant disorders. Eur J Haematol 87: 503-509.

24. Remberger M, Svahn BM, Mattsson J, Ringdén O (2004) Dose study of thymoglobulin during conditioning for unrelated donor allogeneic stem-cell transplantation. Transplantation 78: 122-127.

25. Remberger M, Mattsson J, Svahn BM, Ringdén O (2008) Using reduced intensity conditioning and HLA-identical sibling donors, antithymocyte globulin increases the risk of relapse, which can be overcome by a high stem cell dose. Bone Marrow Transplant 42: 769-771.

26. Svahn BM, Remberger M, Myrbäck KE, Holmberg K, Eriksson B, et al. (2002) Home care during the pancytopenic phase after allogeneic hematopoietic stem cell transplantation is advantageous compared with hospital care. Blood 100: 4317-4324.

27. Suciu S, Mandelli F, de Witte T, Zittoun R, Gallo E, et al. (2003) Allogeneic compared with autologous stem cell transplantation in the treatment of patients younger than 46 years with acute myeloid leukemia (AML) in first complete remission (CR1): an intention-to-treat analysis of the EORTC/ GIMEMAAML-10 trial. Blood 102: 1232-1240.

28. Glucksberg H, Storb R, Fefer A, Buckner CD, Neiman PE, et al. (1974) Clinical manifestations of graft-versus-host disease in human recipients of marrow from HL-A-matched sibling donors. Transplantation 18: 295-304.

29. Shulman HM, Sullivan KM, Weiden PL, McDonald GB, Striker GE, et al. (1980) Chronic graft-versus-host syndrome in man. A long-term clinicopathologic study of 20 Seattle patients. Am J Med 69: 204-217.

30. Carlens $S$, Ringdén $O$, Remberger $M$, Lönnqvist $B$, Hägglund $H$, et al (1998) Risk factors for chronic graft-versus-host disease after bone marrow transplantation: a retrospective single centre analysis. Bone Marrow Transplant 22: 755-761.

31. Hassan Z, Remberger M, Svenberg P, Elbander M, Omazic B, et al. (2007) Hemorrhagic cystitis: a retrospective single-center survey. Clin Transplant 21: 659-667. 
Citation: Ringdén O, Uzunel M, Sadeghi B, Solders M, Uhlin M, et al. (2014) Decreased Risk of Acute Graft-versus-Host Disease Using Reduced Intensity Conditioning Compared to Myeloablative Conditioning is Independent of Donor-Recipient T-cell Chimerism. J Transplant Technol Res 4: 142. doi:10.4172/2161-0991.1000142

Page 8 of 8

32. Mattsson J, Uzunel M, Tammik L, Aschan J, Ringdén O (2001) Leukemia lineage-specific chimerism analysis is a sensitive predictor of relapse in patients with acute myeloid leukemia and myelodysplastic syndrome after allogeneic stem cell transplantation. Leukemia 15: 1976-1985.

33. Ringdén $\mathrm{O}$, Okas $\mathrm{M}$, Uhlin $\mathrm{M}$, Uzunel $\mathrm{M}$, Remberger $\mathrm{M}$, et al. (2008) Unrelated cord blood and mismatched unrelated volunteer donor transplants, two alternatives in patients who lack an HLA-identical donor. Bone Marrow Transplant 42: 643-648.

34. Kaplan EL, Meier P (1958) Nonparametric estimation from incomplete observations. J Am Stat Assoc 53: 457-481.

35. Gooley TA, Leisenring W, Crowley J, Storer BE (1999) Estimation of failure probabilities in the presence of competing risks: new representations of old estimators. Stat Med 18: 695-706.

36. Schetelig J, Oswald O, Steuer N, Radonic A, Thulke S, et al. (2003) Cytomegalovirus infections in allogeneic stem cell recipients after reducedintensity or myeloablative conditioning assessed by quantitative PCR and pp65-antigenemia. Bone Marrow Transplant 32: 695-701.

37. Ferrara JL, Levy R, Chao NJ (1999) Pathophysiologic mechanisms of acute graft-vs.-host disease. Biol Blood Marrow Transplant 5: 347-356.

38. Hill GR, Crawford JM, Cooke KR, Brinson YS, Pan L, et al. (1997) Total body irradiation and acute graft-versus-host disease: the role of gastrointestinal damage and inflammatory cytokines. Blood 90: 3204-3213.

39. Ildstad ST, Wren SM, Bluestone JA, Barbieri SA, Stephany D, et al. (1986) Effect of selective $T$ cell depletion of host and/or donor bone marrow on lymphopoietic repopulation, tolerance, and graft-vs-host disease in mixed allogeneic chimeras (B10 + B10.D2----B10). J Immunol 136: 28-33.
40. Sykes M, Eisenthal A, Sachs DH (1988) Mechanism of protection from graftvs-host disease in murine mixed allogeneic chimeras. I. Development of a null cell population suppressive of cell-mediated lympholysis responses and derived from the syngeneic bone marrow component. J Immunol 140: 29032911.

41. Flynn CM, Hirsch B, Defor T, Barker JN, Miller JS, et al. (2007) Reduced intensity compared with high dose conditioning for allotransplantation in acute myeloid leukemia and myelodysplastic syndrome: a comparative clinical analysis. Am J Hematol 82: 867-872.

42. Atkinson K, Horowitz MM, Gale RP, van Bekkum DW, Gluckman E, et al. (1990) Risk factors for chronic graft-versus-host disease after HLA-identical sibling bone marrow transplantation. Blood 75: 2459-2464.

43. Ringdén O, Paulin T, Lönnqvist B, Nilsson B (1985) An analysis of factors predisposing to chronic graft-versus-host disease. Exp Hematol 13: 1062 1067

44. Storb R, Prentice RL, Sullivan KM, Shulman HM, Deeg HJ, et al. (1983) Predictive factors in chronic graft-versus-host disease in patients with aplastic anemia treated by marrow transplantation from HLA-identical siblings. Ann Intern Med 98: 461-466.

45. Clift RA, Buckner CD, Appelbaum FR, Bearman SI, Petersen FB, et al (1990) Allogeneic marrow transplantation in patients with acute myeloid leukemia in first remission: a randomized trial of two irradiation regimens. Blood 76: 1867-1871.

46. Weisdorf D, Zhang MJ, Arora M, Horowitz MM, Rizzo JD, et al. (2012) Graftversus-host disease induced graft-versus-leukemia effect: greater impact on relapse and disease-free survival after reduced intensity conditioning. Biol Blood Marrow Transplant 18: 1727-1733.

47. Finke J, Bethge WA, Schmoor C, Ottinger HD, Stelljes M, et al. (2009) Standard graft-versus-host disease prophylaxis with or without anti-T-cell globulin in haematopoietic cell transplantation from matched unrelated donors: a randomised, open-label, multicentre phase 3 trial. Lancet Oncol 10: $855-864$ 